\title{
Literatura e cidade rizomáticas ${ }^{1}$
}

\author{
Rhizomatic literature and city \\ Literatura y ciudad rizomáticas \\ André Natã Mello Botton $\odot$ \\ Pontifícia Universidade Católica do Rio Grande do Sul, Porto Alegre, RS, Brasil.
}

\section{RESUMO}

Gilles Deleuze e Félix Guattari apresentam em Mil Platôs o conceito de "rizoma" que se faz na multiplicidade própria que a filosofia suscita. No estudo dos autores, há uma conexão de linhas que se ligam umas às outras na mesma estrutura que as raízes das plantas possuem. Desse modo, o presente estudo desenvolve uma argumentação na relação que a literatura brasileira contemporânea compreende acerca da construção do urbano dentro de sua ficcionalidade. Mais do que representar, os livros seriam expressões rizomáticas tanto na sua ficção quanto na construção urbana que as ações de suas personagens desenvolvem por entre as cidades. Com isso, os livros e as cidades apresentariam formas rizomáticas que estão conectadas umas às outras.

Palavras-chave: Rizoma. Cidade. Literatura.

\begin{abstract}
Gilles Deleuze and Félix Guattari present in Mil Platôs the concept of "rhizome" that is made in the very multiplicity that philosophy provokes. In the study of the authors, there is a connection of lines that bind to each other in the same structure that the roots of the plants have. Thus, the present study develops an argument in the relation that contemporary Brazilian literature understands about the construction of the urban within its fictionality. More than representing, the books would be rhizomatic expressions both in their fictionality and in the urban construction that the actions of their personages develop between the cities. With this, both books and cities would present rhizomatic forms that are connected to each other.
\end{abstract}

Keywords: Rhizome. City. Literature.

\section{RESUMEN}

Gilles Deleuze y Félix Guattari presentan en Mil Platôs el concepto de "rizoma" que se hace en la multiplicidad que suscita la filosofía. En el estudio de los autores, hay una conexión de líneas que se conectan entre sí en la misma estructura que las raíces de las plantas. Así, el presente estudio desarrolla un argumento en la relación que la literatura brasileña contemporánea entiende acerca de la construcción de lo urbano dentro de su ficción. Más que representar, los libros serían expresiones rizomáticas tanto en su ficción como en la construcción urbana que las acciones de sus personajes desarrollan entre las ciudades. Con esto, los libros y las ciudades presentarían formas rizomáticas que están conectadas entre sí.

Palabras clave: Rizoma. Ciudad. Literatura.

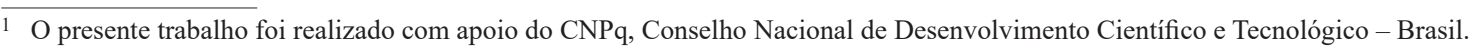


É na multiplicidade que um livro se constrói. É na abertura e no entrecruzamento das mais diversas linhas que as histórias são constituídas. A unicidade, desse modo, não existe mais para si, mas para fora, no entrecruzamento de vidas de personagens que circulam, que atravessam territórios e que partem para fora-de-si. O eu reúne em si vários outros que acabam por interferir na estrutura interna de cada sujeito. Cada vez mais a literatura brasileira contemporânea apresenta em sua estrutura a própria cidade onde está inserida. "O mundo tornou-se caos, mas o livro permanece sendo imagem do mundo [...]" (DELEUZE; GUATTARI, 1995, p. 12). Se havia até pouco tempo uma organização muito bem definida e agrimensada - tanto nas cidades quanto na literatura -, o que se percebe atualmente são sujeitos em trânsito, migrantes, territorialidades cruzadas e sem um início e um fim, mas sempre o meio, o múltiplo.

$\mathrm{O}$ centro perdeu espaço para o meio, para o entrecruzamento. A mudança e o deslocamento são marcas próprias de um tempo que está na velocidade da própria tecnologia. O passado tornou-se muito próximo e as histórias cada vez mais estão presentes enquanto formas múltiplas de diálogos. Modelos estanques e separados não fazem mais parte do mundo contemporâneo, o que se percebe tanto nas geografias das cidades quanto nas estruturas literárias são conexões internas e externas em constante ligação. Em uma imagem: o rizoma.

Se o fim do século XX cria novas utopias, o início do XXI abala todas as estruturas sociais, econômicas, culturais, históricas, políticas e urbanas construídas até aquele momento. Esse período eufórico de emergência de uma nova sociedade, ainda abalada por duas grandes guerras, por governos marcadamente autoritários, por mudanças de classes sociais, de globalização do mundo, de desenvolvimento tecnológico e midiático também alterou a geografia das cidades - agora estruturalmente labiríntica - bem como a estrutura interna do sujeito que as habita.

A cidade moderna é vista como um complexo de ruas que se mesclam e se interpõem, sem início nem fim. Contudo, diferentemente do labirinto, a trilha que se faz não é para o centro, mas para a dispersão, para os "limites" de suas fronteiras. A cidade pós-moderna, segundo David Harvey (2003), é fruto de um processo histórico e cultural que se iniciou ainda na Primeira Guerra Mundial. Segundo o autor, a arquitetura das cidades, com o tempo, foi se organizando para o particular e não mais para um coletivo, de modo que se percebe que o projeto urbano está voltado, em seu desenvolvimento, para a individualidade, como um palimpsesto de formas superpostas, em uma colagem fragmentária de

[...] histórias locais, aos desejos, necessidades e fantasias particulares, gerando formas arquitetônicas especializadas, e até altamente sob medida, que podem variar dos espaços íntimos e personalizados ao esplendor do espetáculo, passando pela monumentalidade tradicional (HARVEY, 2003, p. 69).

Tais contingências influenciaram na construção da cidade contemporânea, assim como em seu enraizamento na vida cotidiana. "Façamos o que fizermos com o conceito, não devemos ler o pós-modernismo como uma corrente artística autônoma; seu enraizamento na vida cotidiana é uma de suas características mais patentemente claras" (HARVEY, 2003, p. 65). Ou seja, o pós-modernismo está presente também nas práticas sociais, econômicas, políticas e culturais da sociedade. Portanto:

O que ocorre no fim do século XX, com o desenvolvimento intensivo e extensivo do capitalismo pelo mundo, abrindo ou reabrindo fronteiras, é a emergência de uma configuração geo-histórica original, dotada de peculiaridades especiais e de movimentos próprios, que se pode denominar global, globalizante, globalizada ou globalismo. Trata-se de uma realidade social, econômica, política e cultural de âmbito transnacional. Pode recobrir, impregnar, mutilar ou recriar as mais diversas formas de nacionalismos, assim como de localismos, provincianismos, regionalismos e internacionalismos, bem como de colonialismos e imperialismos. Nem sempre anula o que preexiste, mas em geral modifica o lugar e o significado do que preexiste. $\mathrm{O}$ globalismo modifica as condições e as possibilidades de espaço e tempo que se haviam constituído e codificado com base no parâmetro geohistórico e mental representado pelo nacionalismo. Desterritorializam-se e reterritorializam-se em outros lugares, em outras durações, as coisas, as gentes e as ideias. Também assim se transforma o mapa do mundo, não só o que pode estar na geografia e na história, mas também o que pode estar nas mentes e corações (IANNI, 1999, p. 20-21).

O globalismo, como configuração histórico-social abrangente do fim do século XX, promove o debate a respeito de conceitos marcadamente territoriais, uma vez que elimina fronteiras e limites fixados - mais uma vez, sob outra perspectiva, aquela visão de fronteiras perde espaço para as conexões que o mundo hodierno cria. A ideia de mudança é o que caracteriza todo esse momento histórico, pois vai além dos limites nacionais, modificando o espaço, a ideia de nação e, principalmente, as pessoas. São realidades que se dinamizam com a globalização e com a formação da sociedade global. Da mesma forma que projetos coletivos e individuais surgem e em um espaço muito curto de tempo envelhecem e morrem, a cidade também se configura, enquanto dinâmica constante de mudanças e de migrações, como fragmento. Segundo Mike Davis (2006), as cidades absorvem cerca de dois 
terços da população mundial. Na segunda metade do século XX, em todo o mundo, houve uma grande migração do meio rural para o urbano. Por conseguinte, as grandes cidades se desenvolveram até se tornarem megalópoles sem centros delimitados ou marcações de fronteiras.

A partir dessa movimentação, os sujeitos que habitam as cidades se constituem como migrantes. Estão em constante deslocamento - não estão no seu lugar e buscam outros espaços. Por esse caminho, transitam em identidades que não são fixas, sem essencialização ou definição de si. O sujeito inserido nesse contexto de migrância também migra de identidade, perde uma identidade primeira e, na medida em que se desloca, modifica-se a si mesmo.

É uma passagem ao outro, um movimento progressivo do Um em direção ao Outro, que infringe as leis do próprio, transpõe as fronteiras da propriedade ou da individualidade, para ir além, sempre, do lugar de onde se vem e de onde se extrai a identidade, para melhor desfazer esse laço imaginário e reatá-lo cada vez em um novo destino, um outro tornar-se que também é um tornar-se outro. Não se trata mais da transformação genética de uma heterogeneidade em uma nova individualidade, como na hibridação, mas do movimento migratório pelo qual se emancipa da origem ou da identidade primeira, em uma espécie de tradução ou de translação de si em outro, para dar-se uma história, um destino ou um tornar-se que não se inscrevem mais na bela continuidade causal de uma memória única e homogênea - pelo que se está religado a uma única fonte, a uma única origem -, mas que reescrevem sua própria constituição como sujeito, a partir de suas diferentes confrontações com a alteridade, em uma gênese ou um percurso definido mais como uma contínua migração do que como um simples retorno sobre si (OUELLET, 2013, p. 152-153, grifo do autor).

Se os lugares são fragmentados, se a cidade está dividida, os sujeitos também estão. Há uma inter-relação de influências entre o eu e o outro em relação ao lugar que ocupam. $\mathrm{O}$ espaço onde o sujeito está inserido diz muito sobre si e isso influencia na possível caracterização da identidade do homem. Há uma troca simétrica entre espaço-sujeito na configuração tanto de um quanto do outro. Os sujeitos em migração encontram-se fragmentados, pois, uma vez que não permanecem nos mesmos locais, suas identidades também se redimensionam e se configuram a partir do espaço que habitam, e vice-versa. É nesse sentido que se pode dizer que o homem vive deslocado, desabrigado, pois antes de não possuir casa, o seu eu, ou a ideia de pessoa que tem de si, também vive exilada. Mesmo assim, o homem que vive nessa cidadelabiríntica é o criador e, ao mesmo tempo, está preso nas malhas da sua cidade.
O homem citadino é presa dessa cidade, está enredado em suas malhas. Não consegue sair desse espaço denso, uma vez que a civilização urbana espraiouse para além dos centros metropolitanos e continua a preencher grandes áreas que gravitam em torno desses centros. A partir da Revolução Industrial, o fenômeno urbano parece ter ultrapassado as fronteiras das "cidades" e ter-se difundido pelo espaço físico. $\mathrm{O}$ signo do progresso transforma a urbanização em movimento centrífugo, gerando a metrópole que se dispersa. Assim, o citadino - homem à deriva - está na cidade como em labirinto, não pode sair dela sem cair em outra, idêntica ainda que seja distinta (GOMES, 2008, p. 68).

A cidade, segundo Renato Cordeiro Gomes, é vista como produto da técnica que o próprio homem construiu e, concomitantemente, é prisioneiro dela. Fruto de um progresso acelerado a partir dos anos 1950, a cidade foi se espalhando pelos seus contornos, criando bairros distantes do centro que, em alguns casos, tornaram-se outras cidades, sem limites e ou demarcações geográficas que as diferenciasse uma da outra. O movimento centrífugo, característica que o autor associa às cidades, acontece não apenas de seu centro para as margens (dentro do "limite" da cidade), mas ele se espalha e cria outras cidades sem limites, quase como apêndices da cidade-metrópole: são as "cidades dormitórios", que dependem de sua metrópole.

Assim, de um centro metropolitano surgem cidades que se dispersam pelos contornos, sem demarcações de início e fim de uma ou outra cidade. Outros centros começam a surgir, em uma tessitura de diferentes formas sem nenhum centro. "As diferenças sociais e culturais dos habitantes das megalópoles refletem-se no tecido urbano, onde se mesclam construções de luxo da arquitetura pósmoderna, reunidas em condomínios fechados, e favelas, cortiços, barriadas, invasões" (FREITAG, 2015, p. 154).

Segundo Harvey, desde 1970 percebe-se uma crescente favelização dos grandes centros urbanos mundiais ${ }^{2}$. No caso brasileiro, não apenas Rio de Janeiro e São Paulo, mas também outras cidades se tornaram metrópoles, passaram, assim, pelo mesmo processo de globalização e de fragmentação. O autor, ao comentar sobre esse crescimento acelerado dos centros urbanos, relaciona a realidade com a representação em romances que apresentam em suas narrativas o mesmo processo de

\footnotetext{
2 O trabalho de Mauricio de Almeida Abreu, A evolução urbana do Rio de Janeiro, apresenta uma série de dados desse crescimento da cidade carioca - desde o seu surgimento no final do século XIX até os anos 1970 - e, por extensão, do processo de urbanização que o Rio de Janeiro e São Paulo sofreram nas últimas décadas. "O aumento do valor do solo, a distância cada vez maior que separava os locais de emprego dos novos loteamentos, o congelamento do aluguéis (que diminuíra em muito a oferta de novas habitações), tudo isso resultou em uma crise habitacional generalizada, que afetou, principalmente, a população mais pobre Consequentemente, multiplicou-se a população favelada e proliferaram novamente as casas de cômodo" (ABREU, 1988, p. 116).
} 
desenvolvimento e crescimento da malha citadina. Isso pode ser visto pela superposição de histórias e narrativas individuais que permanecem presentes tanto na realidade quanto na ficção nos textos literários.

A superposição, em tantos romances pós-modernos, de diferentes mundos entre os quais prevalece uma "alteridade" incomunicativa num espaço de coexistência tem uma estranha relação com a crescente favelização, enfraquecimento e isolamento da pobreza e das populações minoritárias no centro ampliado das cidades britânicas e norte-americanas. Não é difícil ler um romance pós-moderno como um corte transversal metafórico das paisagens sociais em fragmentação, das subculturas e modos locais de comunicação de Londres, Chicago, Nova Iorque e Los Angeles. Como a maioria dos indicadores sociais sugere um forte aumento da favelização a partir de 1970, é proveitoso pensar a ficção pós-moderna como uma possível mimese desse fato (HARVEY, 2003, p. 110).

Nessa lista de cidades citadas pelo geógrafo britânico, pode-se incluir também tantas outras cidades brasileiras que tiveram o mesmo processo de urbanização e favelização nessa mesma época. O desenvolvimento urbano dessa época é representado nas páginas da literatura. Ou seja, o crescimento acelerado das cidades e a consequente superpopulação podem ser vistos tanto nas ficções quanto na própria realidade da época apresentada por Harvey. Contudo, quando o estudo do sujeito está voltado para as obras literárias, surge uma outra cidade que é construída a partir dos deslocamentos que as personagens fazem pelas tramas urbanas. São sujeitos em migrância que percorrem os mais diferentes espaços citadinos e constroem a sua identidade bem como a identidade do local onde estão inseridos.

Portanto:

A cidade escrita é, então, resultado da leitura, construção do sujeito que lê, enquanto espaço físico e mito cultural, pensando-a como condensação simbólica e material e cenário de mudança, em busca de significação. Escrever, portanto, a cidade é também lê-la, mesmo que ela se mostre ilegível à primeira vista; é engendrar uma forma para essa realidade sempre móvel. Mapear seus sentidos múltiplos e suas múltiplas vozes e grafias é uma operação poética que procura apreender a escrita da cidade e a cidade como escrita, num jogo aberto à complexidade (GOMES, 2009, p. 24).

O autor dessas obras possui uma dupla função: ler e escrever a cidade. Ele constrói o espaço citadino a partir da sua visão e ao mesmo tempo cria um mundo através dos deslocamentos que as suas personagens engendram por entre caminhos muitos vezes desconhecidos e que ganham significados novos a partir da vivência e das histórias construídas nesses movimentos. No plano urbano, as personagens ao transitar pelas ruas, leem a cidade e fazem parte desse espaço. Ao mesmo tempo em que estão inseridas nesse contexto, elas escrevem, com a própria vida, com o seu andar, a história e transformamse em material simbólico do seu local. Assim como as personagens são múltiplas, a cidade torna-se múltipla de sentidos e significados que lhe são dados pelas vias que circulam em uma trama complexa e multicultural. $\mathrm{Na}$ literatura, esse processo se expressa na forma como representa esse espaço. O espaço urbano, desse modo, não deve ser considerado apenas em sua concretude, mas na sua significação, para se poder perceber os meandros de vidas que estão em constante deslocamento. Ao mesmo tempo, quando a cidade é considerada em vista de uma significação para além de sua concretude, é possível criar relações com outros espaços que nem sempre estão diretamente relacionados.

Em uma visão oposta, Barbara Freitag apresenta a sociedade brasileira dividida em duas: uma parcela da população segue o modelo americano de habitação, sendo uma sociedade informacional e a "outra metade mal saiu da escravidão introduzida no período colonial e que, uma vez abolida, deixou contingentes imensos da população sem teto, sem trabalho, sem educação, sem saúde, sem espaço legalizado nos grandes centros urbanos" (2015, p.134). A polarização da sociedade, segundo a autora, explica e dá forma ao conceito de "cidade brasileira partida", pois, apesar de milhares de habitantes morarem nas favelas, às vezes, nem registro civil possuem. Por vezes, o local onde moram nem consta em mapas, pois não há nome de rua, número de casa, ou seja, nem endereço têm. Em outras palavras, não são legitimadas e não possuem visibilidade social.

Ao contrário dessa dicotomia - que muitas vezes se faz presente nos centros urbanos -, propõe-se um outro método de análise e de estudo para a cidade e para a literatura contemporâneas: o modelo rizomático, conforme apresentado por Gilles Deleuze e Félix Guattari, em Mil Platôs.

\begin{abstract}
Num rizoma, ao contrário, cada traço não remete necessariamente a um traço linguístico: cadeias semióticas de toda natureza são aí conectadas a modos de codificação muito diversos, cadeias biológicas, políticas, econômicas, etc., colocando em jogo não somente regimes de signos diferentes, mas também estatutos de estados de coisas (DELEUZE; GUATTARI, 1995, p. 13).
\end{abstract}

Considerar o rizoma em algum estudo é perceber as ligações existentes entre as coisas e entre as palavras, enquanto conceitos. Os labirintos das cidades, conforme apresentado por Gomes (2008), são histórias descentradas sem um fim ou começo, não há limites rígidos entre os 
espaços, bem como não há um centro nesse labirinto, o que existe são cruzamentos de narrativas que vez por outra se atravessam uma sobre a outra: "qualquer ponto de um rizoma pode ser conectado a qualquer outro e deve sê-lo" (DELEUZE; GUATTARI, 1995, p. 13). Mesmo assim, as conexões que são feitas em um rizoma são estabelecidas a partir de linhas que se cruzam. Não há pontos iniciais ou finais, mas um agenciamento que cresce na multiplicidade à medida que aumenta suas conexões em um plano de consistência achatado e horizontal que se expande para fora. O que existe são pontos de estudo, pontos de cruzamento estão relacionados a outros conceitos. Daí o agenciamento existente.

Nesse sentido, quando Harvey (2003) exemplifica o corte vertical que há nos romances pós-modernos, quando representam a realidade de algumas cidades - Los Angeles, Nova Iorque, Londres ou Chicago -, o que ele está propondo é uma ruptura ou um foco em um determinado ponto no rizoma que une todos esses centros urbanos. Da mesma forma no caso brasileiro, quando uma cidade ou romance é elegido para estudo o que acontece é o rompimento de conexões, uma vez que é impossível falar exclusivamente da cidade de São Paulo sem remeter a alguma situação do Rio de Janeiro e vice-versa, por exemplo. Essa linhas que conectam uma cidade à outra, ou um romance a outro, tornam-se complementares e não param de se remeter igualmente. Em um outro exemplo, dentro da literatura brasileira contemporânea, falar em Ferréz levará em alguma medida a referenciar também Paulo Lins, dentro da produção dos dois autores e na importância mútua que os seus Capão pecado e Cidade de Deus tiveram no contexto hodierno. São linhas de fuga que em algum momento levarão a uma raiz mais profunda que está em ligação com outras linhas e contextos sociais, políticos, culturais e econômicos. Não há extratificação ou desterritorialização binária, há conexão e multiplicidade. Um livro ou uma cidade tornam-se nada mais que produtos "de uma seleção ativa e temporária a ser recomeçada" (DELEUZE; GUATTARI, 1995, p.16). Dentro das relações que se entrechocam, não é mais possível afirmar uma evolução ou mimetismo, mas apenas um rizoma que une linhas diferentes.

É a mesma coisa quanto ao livro e ao mundo: o livro não é a imagem do mundo segundo uma crença enraizada. Ele faz rizoma com o mundo, há evolução a-paralela do livro e do mundo, o livro assegura a desterritorialização do mundo, mas o mundo opera uma reterritorialização do livro, que se desterritorializa por sua vez em si mesmo no mundo (se ele é disto capaz e se ele pode). O mimetismo é um conceito muito ruim, dependente de uma lógica binária, para fenômenos de natureza inteiramente diferente (DELEUZE; GUATTARI, 1995, p. 18).
Um livro é a exteriorização do seu mundo, um devir-mundo, de modo que ele próprio faz a sua ruptura ao mesmo tempo em que está enraizado e se conecta com outros livros. Destacar a forma rizomática do livro é perceber a sua conexão com o mundo exterior a si. Mais do que decalcar cada elemento de estudo (tanto a cidade quanto o livro, neste caso), torna-se importante perceber as ligações, ou, em última instância, religá-los às linhas convergentes que esses componentes possuem. Destacar as aberturas e as possíveis entradas que cada rizoma, ou mapa implica, permite que outros rizomas sejam formados. Criando, por sua vez, uma outra formação conectada a uma primeira que não estabelece uma relação binária, mas simétrica na sua multiplicidade. Não há valoração entre os termos ou produtos, pelo contrário, há exteriorização de componentes intrinsecamente conectados. Cada um de seus traços não remete necessariamente a um traço de mesma natureza, "ele põe em jogo regimes de signos muito diferentes, inclusive estados de não-signos" (DELEUZE; GUATTARI, 1995, p. 30).

Ao evidenciar o curso que as vidas das personagens ganham pelos caminhos da cidade dentro de um livro, percebe-se que as próprias linhas rizomáticas citadinas são refeitas. As ações não possuem centro, mas conexões. "O que quer dizer que o espaço, hoje mais do que nunca, é constitutivo da personagem, seja ela nômade ou não" (DALCASTAGNÈ, 2012, p. 109). É aquele jogo simétrico entre personagem-espaço. Tanto as ações das personagens constituem a cidade quanto esta necessita daquela para existir. Um exemplo claro dessa relação está em Eles eram muitos cavalos, de Luiz Ruffato. A narrativa não possui uma personagem principal, mas uma cidade principal por onde diversas personagens transitam e, em algumas vezes, se cruzam. São como as linhas de um rizoma que se fazem e entrecruzam, estão como perdidas dentro de si mesmas e fora de seus espaços. O que elas possuem em comum? São Paulo. O livro de Ruffato possui uma estrutura rizomática que situa o leitor quanto ao tempo e ao espaço; no entanto, as personagens, algumas nomeadas e outras não, se movimentam por entre ruas, avenidas, becos e histórias que são apresentadas ao leitor conforme as ações individuais que realizam. "Por isso mesmo é possível dizer que nenhum espaço se define a priori por si próprio. Ele é sempre o espaço de alguma coisa, uma relação (espaço-temporal) informada e/ou preenchida por outra presença" (DALCASTAGNÈ, 2015, p. 87).

A presença de personagens na literatura brasileira contemporânea se faz a partir do espaço próprio que cada uma habita. Em uma associação à forma rizomática aqui apresentada, pode-se dizer que dentro desse modelo não haveria um centro específico ou mesmo uma margem, mas linhas de fuga que possibilitariam a entrada e a saída desses espaços nas linhas próprias que compõem 
um rizoma. Focalizando, nessa medida, a literatura marginal-periférica - considerada neste contexto como rizoma -, enquanto manifestação cultural de autores que estão produzindo seus textos a partir de contextos sociais periféricos, uma outra produção literária se apresenta enquanto exemplo e ao mesmo tempo sintoma de um rizoma citadino em constante mudança e deslocamento: O sol na cabeça, de Geovani Martins. O livro é uma reunião de treze contos de personagens que moram nas mais diversas favelas do Rio de Janeiro. Dessa forma, circulam por espaços marginais (dentro de uma sociedade brasileira excludente e marcadamente preconceituosa), mas que dentro da dinâmica própria da estrutura narrativa centralizam o seu discurso a partir do cotidiano em que estão inseridas. Nesse sentido, é possível afirmar que o rizoma construído pelo livro está em relação e ao mesmo tempo apresenta as linhas próprias com que são delineadas as ruas, vielas e becos das favelas por onde as personagens de Geovani Martins circulam. Territorialmente, as favelas apresentadas na obra são distantes umas das outras, no entanto, as personagens circulam por elas como se estivessem muito próximas na geografia da cidade. Ou seja, a percepção geográfica das favelas é feita enquanto rizoma, pois há conexão entre todos esses espaços. A ligação que esses locais possuem dentro da trama que se constrói em cada conto evidencia um rizoma que está ligado por linhas sociais e que descentraliza aquilo dito como central na cidade carioca. Em outras palavras, o próprio centro das narrativas são as favelas e a cidade do Rio de Janeiro é uma linha de fuga para a forma rizomática da periferia. Há conexão entre todos os espaços, mas é o meio por onde as personagens circulam que se torna fundamental nos contos. "É que o meio não é uma média; ao contrário, é o lugar onde as coisas adquirem velocidade" (DELEUZE; GUATTARI, 1995, p.35). Na forma rizomática que o livro constrói bem como no modelo de rizoma da cidade, há uma combinação explícita entre favela e texto. E a mudança que se dá nesse contexto gira em torno do espaço por onde histórias se cruzam em uma territorialidade construída pelas ações de cada personagem. "Ou seja, o espaço é uma construção que muda constantemente, conforme os sujeitos que nele se encontram, que por ele transitam. Esta percepção de espaço também muda o entendimento de 'lugar' (place)" (LEHNEN, 2015, p. 122).

Mais do que nunca o espaço da cidade dentro da literatura tornou-se algo que está em constante mudança e permite que outros olhares sejam dados. Compreender cidade e literatura enquanto formas rizomáticas não exclui outros olhares e outras concepções acerca desses conceitos, pelo contrário, a abertura própria que o rizoma possui permite que outras teorias e outros olhares sejam dados para uma mesma situação. Em alguma medida, tudo estaria conectado enquanto mapa de relações conceituais e simbólicas. Por outro lado, assim como o rizoma permite que outras linhas sejam construídas, a falta de um território específico também possibilita a construção e a mudança dos espaços.

A cidade é um símbolo da sociabilidade humana, lugar de encontro e de vida em comum - e, nesse sentido, seu modelo é a polis grega. Mas é também um símbolo da diversidade humana, espaço em que convivem massas de pessoas que não se conhecem, não se reconhecem ou mesmo se hostilizam; e aqui o modelo não é mais a cidade grega, e sim Babel. Mais até do que a primeira, essa segunda imagem, a da desarmonia e da confusão, é responsável pelo fascínio que as cidades exercem, como locais em que se abrem todas as possibilidades (DALCASTAGNÈ, 2012, p. 110).

A dinamicidade própria do urbano e da literatura são evidências claras da relação que possuem enquanto formas rizomáticas. Como já referido, é o meio, o movimento que constrói o urbano e não mais a solidez ou a presença estável de um território. O entrecruzamento de histórias das personagens possibilita que linhas das mais diversas estejam conectadas em um mesmo espaço. Personagens transitam por entre ruas e avenidas e desenvolvem pelo seu andar um rizoma citadino. Para o leitor cabe a tarefa de percorrer as mesmas linhas e perceber a velocidade com que as personagens transitam pelos espaços das cidades, com isso, acabará descobrindo também o próprio espaço urbano que a ficção está construindo.

Como se vê, distinguir o espaço na narrativa contemporânea é uma tarefa tão mais complicada quanto maior parece ser a tensão que ele estabelece com as personagens que o atravessam ou que o ocupam. Uma vez que as longas descrições do romance do século XIX foram abolidas em nome da agilidade dos nossos tempos, resta-nos uma ambientação mínima, que exige do leitor o reconhecimento quase instantâneo dos diferentes códigos sociais embutidos em cada situação. Ou seja, se antes tínhamos a farta apresentação de móveis, utensílios e vestimentas, além de detalhes da própria casa e da rua onde ela estaria instalada, para esclarecer a posição de determinada personagem, hoje, precisamos nos ater ao modo como ela fala, como gesticula e se comporta diante de outras para saber de onde ela vem, e quem ela é. Mais do que nunca, a personagem transporta seu próprio espaço, por mais reduzido que ele seja (DALCASTAGNÈ, 2012, p. 128-129).

São as linhas que as personagens trilham dentro do romance que constroem o espaço urbano. A territorialidade fixa não é mais elemento constitutivo da literatura. As paradas são raras, não há um início ou um 
fim estabelecidos. O meio se tornou uma característica do fazer literário.

Assim como um mapa possui várias entradas, em oposição ao decalque, o rizoma apresenta em sua estrutura aberturas que permitem a inserção de outros conceitos e outras ideias. Desse modo, há a possibilidade de conexão com outros campos que podem ampliar ao máximo a abertura de um plano de consistência. São de dimensões movediças que o rizoma abarca em si as mais diversas unidades.

[...] o rizoma é feito somente de linhas: linhas de segmentaridade, de estratificação, como dimensões, mas também linha de fuga ou de desterritorialização como dimensão máxima segundo a qual, em seguindo-a, a multiplicidade se metamorfoseia, mudando de natureza (DELEUZE; GUATTARI, 1995, p. 30).

É como se várias histórias se encontrassem em um determinado ponto e a partir dali pudesse se ver o todo. A formação própria desse encontro seria o rizoma na sua forma mais genuína. Na literatura brasileira contemporânea, outro exemplo que é característico dessa formação rizomática de histórias que se confrontam é o livro Becos da memória, da autora mineira Conceição Evaristo. O romance gira em torno do desmonte de uma favela, as histórias são narradas ora por um narrador, ora por uma menina ou por algum dos moradores daquele espaço. O que eles possuem em comum? A favela onde habitam e ao mesmo tempo procuram em si mesmos e nos outros ter esperança para recomeçar as suas vidas. A narrativa é explícita quanto à forma rizomática desde o título, pois por entre os becos tanto do espaço quanto das memórias, várias histórias são contadas ao leitor. Ao percorrer as vielas de uma favela em desconstrução, é como se o rizoma fosse também ao mesmo tempo sendo descontruído e reconstruído: juntamente com o espaço constituinte da cidade - a favela -, o rizoma composto por linhas das mais diversas é desmontado, contudo, ao tornar presente pela diegese as lembranças de várias personagens, uma outra forma rizomática é acionada: a da memória. Para Deleuze e Guattari (1995), há dois tipos de memória: a curta e a longa, "a memória curta é de tipo rizoma, diagrama, enquanto que a longa é arborescente e centralizada (impressão, engrama, decalque ou foto)." (1995, p. 24). Assim, em Becos da memória, a descontinuidade própria da narrativa, bem como a construção coletiva que ela possui, consente que estrutura interna da obra seja construída por meio da forma rizomática. Ou seja, se o livro é a forma de eternizar em si as mais diversas lembranças, Conceição Evaristo ao recuperar em sua obra as mais diversas histórias, constrói um rizoma por meio de memórias curtas, bem como não as encerra em si. Mas deixa o livro em aberto para que outras histórias também sejam adicionadas a ele.
Mais uma vez, o movimento próprio de personagens em migrância, bem como o devir que há na essência da forma rizomática, estão presentes no texto.

Por fim, conceber a cidade e a literatura nas suas formas rizomáticas é evidenciar os estudos para outra percepção do urbano e da ficção, em que as formas não se excluem, mas se tornam complementares visto as conexões que podem ser feitas a partir da abertura própria do rizoma.

Oposto ao grafismo, ao desenho ou à fotografia, oposto aos decalques, o rizoma se refere a um mapa que deve ser produzido, construído, sempre desmontável, conectável, reversível, modificável, com múltiplas entradas e saídas, com suas linhas de fuga (DELEUZE; GUATTARI, 1995, p. 31).

O pensamento deleuze-guattariano se desenvolve por meio de conexões que podem sempre ser feitas. Não há espaços para rompimentos bruscos ou para ações excludentes. A escrita, para os dois pensadores, é configurada como uma saída de si, uma linha de fuga que está sempre em direção a um outro. Enquanto conceito movemente e da imanência, o rizoma está sempre associado a algo de concreto que a ele faz relação, seja um livro ou mesmo uma cidade, como foram estudados neste texto teórico. A descentralidade própria dos tempos hodiernos é materialidade bruta a ser estudada sob o viés da filosofia trazida na obra de Deleuze e Guattari. O social não é esquecido, mas evidenciado e discutido ao longo dessa filosofia da imanência. Perceber os mais diversos contextos onde diferentes sujeitos estão dispostos faz parte também do trabalho desses dois pensadores.

A literatura e a cidade ao serem concebidas como rizomas tornam-se mais que unidades, mas se fazem enquanto dimensões, direções movediças sem começo nem fim, mas um meio pelas quais outros rizomas podem crescer e transbordar. Perceber as suas conexões é eliminar divisões, e, por outro caminho, possibilita identificar agenciamentos que põem em conexão as multiplicidades próprias de cada conceito.

\section{Referências}

ABREU, Mauricio de Almeida. A Evolução Urbana do Rio de Janeiro. 2. ed. Rio de Janeiro: IPLANRIO/ZAHAR, 1988. https://doi.org/10.17771/pucrio.acad.19192

DALCASTAGNÈ, Regina. Literatura brasileira contemporânea: um território contestado. Rio de Janeiro: Editora da UERJ, 2012.

DALCASTAGNÈ, Regina. A cidade como uma escrita possível. In: DALCASTAGNÈ, Regina. AZEVEDO, Luciene. (org.). Espaços possíveis na literatura brasileira contemporânea. Porto Alegre: Zouk, 2015. p. 85-100. https:// doi.org/10.17851/2358-9787.24.1.203-206 
DAVIS, Mike. Planeta favela. Trad. Beatriz Medina. São Paulo: Boitempo, 2006.

DELEUZE, Gilles; GUATTARI, Félix. Mil Platôs:

capitalismo e esquizofrenia. Trad. Aurélio Guerra Neto e Célia Pinto Costa. Rio de Janeiro: Editora 34, 1995. v. 1.

FREITAG, Barbara. Teorias da cidade. 4. ed. Campinas, SP: Papirus, 2015.

GOMES, Renato Cordeiro. Todas as cidades, a cidade. 2. ed. Rio de Janeiro: Rocco, 2008.

GOMES, Renato Cordeiro. A cidade, a literatura e os estudos culturais: do tema ao problema. Ipotesi: revista de estudos literários, Juiz de fora, v. 3, n. 2, p. 19-30, 2009. Disponível em: http://www.ufjf.br/revistaipotesi/files/2009/12/ACIDADE-A-LITERATURA-E-OS-ESTUDOS1.pdf. Acesso em: nov. 2015. https://doi.org/10.17851/2317-2096.19.3.29-45

HARVEY, David. Condição pós-moderna. Uma pesquisa sobre as Origens da Mudança Cultural. Trad. Adail Ubirajara Sobral e Maria Stela Gonçalves. 12. ed. São Paulo: Edições Loyola, 2003.

IANNI, Octávio. A era do globalismo. In: OLIVEIRA, Flávia Arlanch Martins de (org.). Globalização, regionalização e nacionalismo. São Paulo: Editora Unesp, 1999. p. 15-41.

LEHNEN, Leila. Cartografias móveis: mapeando as margens na literatura brasileira contemporânea. In: DALCASTAGNÈ, Regina. AZEVEDO, Luciene (org.). Espaços possíveis na literatura brasileira contemporânea. Porto Alegre: Zouk, 2015. p. 118-135. https://doi.org/10.17851/2358-9787.24.1. 203-206

OUELLET, Pierre. Palavras migratórias. In: HANCIAU, Nubia. DION, Sylvie. (org.). A literatura na história a história na literatura: textos canadenses em tradução. Rio Grande: Editora da FURG, 2013, p. 145-170.

Recebido em: 7/1/2019.

Aprovado em: 16/9/2019.

Publicado em: 21/12/2019.

Autor:

André Natã Mello Botton

Mestre e doutorando, Pontifícia Universidade Católica do Rio Grande do Sul, Porto Alegre, RS, Brasil.

Orcid: http://orcid.org/0000-0002-2136-7544

E-mail: andre.botton@gmail.com

Endereço: Av. Ipiranga, 6681, Prédio 8 - Partenon

90619-900, Porto Alegre, RS, Brasil 